Gut, 1977, 18, 833-835

\title{
Effect of cigarette smoking on the lower oesophageal sphincter
}

\author{
Assessment of normal and symptomatic patients using the rapid pull- \\ through technique of oesophageal manometry
}

\author{
D. K. CHATTOPADHYAY, M. G. GREANEY, AND T. T. IRVIN
}

From the University Surgical Unit, Royal Infirmary, Sheffield

SUMMARY Obervations on the effect of smoking on lower oesophageal sphincter pressure (LOSP) are based on station pull-through techniques of oesophageal manometry and recent studies have suggested that these techniques are inaccurate. Reproducible measurements of LOSP may be achieved with a rapid pull-through (RPT) method of manometry. This method was used to determine the effect of cigarette smoking on LOSP in 10 asymptomatic volunteers and in a group of 10 patients with symptoms of gastro-oesophageal reflux. Basal LOSP measurements in the two groups were not significantly different but LOSP was reduced by $19 \%$ in asymptomatic subjects $(\mathrm{P}<0.01)$ and by $21 \%$ in symptomatic patients $(\mathrm{P}<0.02)$ during cigarette smoking. The results suggest that smoking should be avoided in the clinical management of gastro-oesophageal reflux.

It is alleged that the presence of a physiological lower oesophageal sphincter is an important factor in the prevention of gastro-oesophageal reflux and several studies have attempted to define the neural and hormonal factors which may regulate lower oesophageal sphincter pressure (Dodds et al., 1976a).

Some of these observations may have clinical relevance in the management of symptomatic gastro-oesophageal reflux and it has been suggested that cigarette smoking has important effects on lower oesophageal sphincter pressure (LOSP). Clinical observations have suggested that heartburn is linked with cigarette smoking (Stanciu and Bennett, 1972; Salter, 1974) and it has been reported that smoking causes a reduction in LOSP in manometric studies (Dennish and Castell, 1971; Stanciu and Bennett, 1972). However, these manometric observations were based on station pull-through techniques of oesophageal manometry and recent studies have shown that these techniques provide unreliable measurements of LOSP (Dodds et al., 1975). The variables which affect LOSP measurements have been defined (Winans, 1972; Dodds

Received for publication 28 March 1977 et al., 1974, 1976b) and it has been shown that reproducible measurements of LOSP may be achieved with a rapid pull-through (RPT) technique of oesophageal manometry (Dodds et al., 1976b).

In the present study, the RPT method of oesophageal manometry was used to determine the effects of cigarette smoking on LOSP.

\section{Methods}

\section{SUBJECTS}

The studies were performed in 10 patients aged 18-74 years, with symptoms of gastro-oesophageal reflux and proven hiatal herniation, and in 10 healthy control subjects aged 34-66 years. The symptomatic subjects (eight male and two female) complained of retrosternal discomfort, acid regurgitation and heartburn, and in each case a sliding hiatus hernia was demonstrated on a barium meal. Each subject had a positive acid-perfusion test (Bennett and Atkinson, 1966) and macroscopic features of oesophagitis were found at fibrescopic oesophagoscopy in eight cases. Ten male control subjects had no symptoms of gastro-oesophageal reflux and were studied during an elective admission to hospital for the treatment of a groin hernia or varicose veins.

The purpose of the study was explained to each subject and informed consent was obtained. 
MANOMETRIC TECHNIQUE

LOSP was measured with four polyvinyl catheters $2 \mathrm{~mm}$ in internal diameter, with distal end-openings located in a radial fashion in the oesophageal lumen at the same axial level. The catheters were perfused with water at a constant rate of $5 \mathrm{ml} / \mathrm{min}$ using a non-compliant hydraulic perfusion system (Koelz et al., 1975). The intraluminal pressures were transmitted to transducers (Statham P23 series), the output from each transducer was amplified (Disa type 14 F. 46 uromanometer, Ampa PR 831 preamplifier), and the measurements were recorded on a thermal pen recorder (Hewlett-Packard 7758A). Occlusion studies of the infused catheter system in bench tests showed a pressure response rate which exceeded $20 \mathrm{k} \mathrm{Pa} / \mathrm{s}$. Dodds et al. (1976b) have shown that a pressure response in excess of $20 \mathrm{k} \mathrm{Pa} / \mathrm{s}$ is required for accurate measurements of LOSP.

The subjects were studied in the supine position after an overnight fast and the catheter assembly was passed through the nose. During RPT measurements, respiration and swallowing were suspended for 10 seconds, and the manometric catheters were withdrawn through the lower oesophageal sphincter at a constant speed of $1 \mathrm{~cm} / \mathrm{s}$ using a motor-driven moveable catheter mount (Allspeeds Ltd., Accrington). LOSP was calculated as the mean of the recordings of the four sensors at each pull-through, expressed as $\mathbf{k ~ P a}$ above gastric pressure.

\section{EFFECT OF SMOKING}

RPT measurements of LOSP were made at intervals of five minutes for one hour and the study was divided into four periods each lasting 15 minutes: from 0-15 minutes basal LOSP measurements were made; from 15-30 minutes measurements were made as the subject puffed an unlit cigarette; from $30-45$ minutes LOSP was recorded during the smoking of two cigarettes; and from 45-60 minutes LOSP was measured when smoking had ceased.

STATISTICAL ANALYSIS

Student's $t$ test for paired observations was used to determine the significance of changes in LOSP.

\section{Results}

The mean $( \pm$ SEM) basal LOSP in symptomatic subjects $(3.20 \pm 0.17 \mathrm{k} \mathrm{Pa})$ was not significantly different from that of controls $(3.52 \pm 0.18 \mathrm{k} \mathrm{Pa})$.

\section{ASYMPTOMATIC SUBJECTS (CONTROLS)}

There was no significant change in LOSP when asymptomatic subjects puffed an unlit cigarette (Fig. 1) but the mean LOSP fell during cigarette smoking to a value of $2 \cdot 84 \pm 0.12 \mathrm{k} \mathrm{Pa}$ and this was a significant reduction compared with basal LOSP measurements $(t=3 \cdot 21, \mathrm{P}<0.01)$. When smoking ceased the mean LOSP rose to a value of $3 \cdot 81 \pm 0.18 \mathrm{k} \mathrm{Pa}$.

\section{SYMPTOMATIC SUBJECTS}

Similar changes in LOSP occurred in subjects with hiatal herniation and symptomatic gastro-oesophageal reflux (Fig. 2). During cigarette smoking the mean LOSP fell to $2.52 \pm 0.15 \mathrm{k} \mathrm{Pa}$. This value was significantly lower than basal measurements ( $t=3.0, \mathrm{P}<0.02$ ) but basal values of LOSP were rapidly restored when smoking ceased.

\section{Discussion}

Recent studies have shown that measurements of LOSP obtained with the standard station or intermittent pull-through techniques of oesophageal manometry have a low degree of reproducibility (Dodds et al., 1975). Several factors account for the variability of these measurements, including the radial asymmetry of the lower oesophageal high

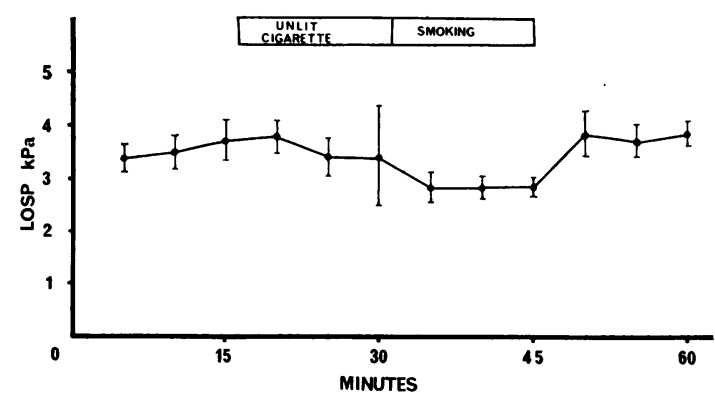

Fig. 1 Mean values $( \pm S E M)$ of LOSP in asymptomatic subjects (controls).

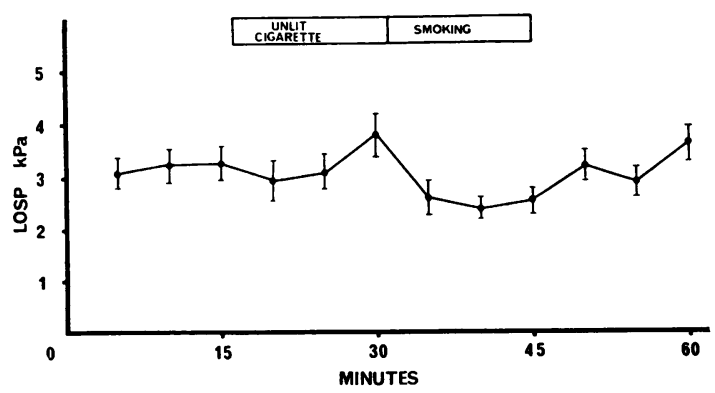

Fig. 2 Mean values ( $\pm S E M)$ of LOSP in symptomatic subjects. 
pressure zone (Winans, 1972), the effects of respiration and respiratory movements of the oesophagus (Dodds et al., 1974), and the infusion rate and compliance of the catheter perfusion system (Stef et al., 1974; Dodds et al., 1976b). These variables may be avoided with the use of an RPT technique of manometry, a non-compliant hydraulic perfusion system with a high infusion rate, and multiple oesophageal catheters with openings which are radially orientated to the oesophageal lumen (Dodds et al., 1976b).

In the present study, RPT measurements of LOSP confirmed that cigarette smoking caused a reduction in LOSP both in normal subjects and in patients with symptoms of gastro-oesophageal reflux. The changes in LOSP were less marked than those described in previous studies using station pullthrough methods of oesophageal manometry. Dennish and Castell (1971) found a 37\% reduction in LOSP in healthy volunteers during cigarette smoking, and Stanciu and Bennett (1972) recorded a $41 \%$ reduction in LOSP in patients with symptoms of gastro-oesophageal reflux. In RPT measurements, we found a $19 \%$ reduction in LOSP in control subjects, and a $21 \%$ reduction in symptomatic patients. As in the previous studies, it was found that the changes in LOSP were confined to the period during which cigarette smoking occurred. The effects of smoking on LOSP are probably due to the nicotine content of the cigarette smoke. It has been shown that nicotine causes relaxation of the circular muscle of the lower oesophageal sphincter in vitro (Ellis et al., 1960; Misiewicz et al., 1969).

Previous measurements of basal LOSP using station pull-through methods of manometry have revealed no consistent difference between asymptomatic subjects and patients with symptoms of gastrooesophageal reflux (Siegel and Hendrix, 1963; Stanciu and Bennett, 1974), and similar results were observed in the present study with the RPT method of manometry. It seems unlikely, therefore, that any meaningful interpretation may be made from basal LOSP measurements and the precise significance of changes in LOSP in response to various mechanical, hormonal, or neural stimuli will be apparent only after further use of the RPT technique. With regard to the effect of smoking on LOSP, however, there is additional direct evidence that smoking causes gastro-oesophageal reflux. Stanciu and Bennett (1972) found that there was a consistent relationship between cigarette smoking and the occurrence of acid reflux during measurements of lower oesophageal pH. Thus, as Salter (1974) has suggested, there seem to be reasonable grounds for advising patients with reflux symptoms to stop smoking.

\section{References}

Bennett, J. R., and Atkinson, M. (1966). Oesophageal acidperfusion in the diagnosis of precordial pain. Lancet, 2 , 1150-1152.

Dennish, G. W., and Castell, D. O. (1971). Inhibitory effect of smoking on the lower esophageal sphincter. New England Journal of Medicine, 284, 1136-1137.

Dodds, W. J., Hogan, W. J., and Miller, W. N. (1976a). Reflux esophagitis. American Journal of Digestive Diseases, 21, 49-67.

Dodds, W. J., Hogan, W. J., Stef, J. J., Miller, W. N., Lydon, S. B., and Arndorfer, R. C. (1975). A rapid pullthrough technique for measuring lower esophageal sphincter pressure. Gastroenterology, 68, 437-443.

Dodds, W. J., Stef, J. J., and Hogan, W. J. (1976b). Factors determining pressure measurement accuracy by intraluminal esophageal manometry. Gastroenterology, 70, 117-123.

Dodds, W. J., Stewart, E. T., Hogan, W. J., Stef, J. J., and Arndorfer, R. C. (1974). Effect of esophageal movement on intraluminal esophageal pressure recording. Gastroenterology, 67, 592-600.

Ellis, F. G., Kauntze, R., and Trounce, J. R. (1960). The innervation of the cardia and lower oesophagus in man. British Journal of Surgery, 47, 466-472.

Koelz, H. R., Brändli, H. H., Blum, A. L. (1975). Simple perfusion pump for gastrointestinal manometry. Lancet, 2, 1075.

Misiewicz, J. J., Waller, S. L., Anthony, P. P., and Gummer, J. W. P. (1969). Achalasia of the cardia: pharmacology and histopathology of isolated cardiac sphincteric muscle from patients with and without achalasia. Quarterly Journal of Medicine, 38, 17-30.

Salter, R. H. (1974). Lower oesophageal sphincter. Therapeutic implications. Lancet, 1, 347-349.

Siegel, C. I., and Hendrix, T. R. (1963). Esophageal motor abnormalities induced by acid perfusion in patients with heartburn. Journal of Clinical Investigation, 42, 686-695.

Stanciu, C., and Bennett, J. R. (1972). Smoking and gastrooesophageal reflux. British Medical Journal, 3, 793-795.

Stanciu, C., and Bennett, J. R. (1974). Correlation between a physiological test of gastro-oesophageal reflux and sphincter squeeze. In Proceedings of the Fourth International Symposium on Gastrointestinal Motility, pp. 131138. Edited by E. E. Daniel. Mitchell: Vancouver.

Stef, J. J., Dodds, W. J., Hogan, W. J., Linehan, J. H., and Stewart, E. T. (1974). Intraluminal esophageal manometry: an analysis of variables affecting recording fidelity of peristaltic pressures. Gastroenterology, 67, 221-230.

Winans, C. S. (1972). Manometric asymmetry of the lower esophageal high pressure zone. Gastroenterology, 62, 830. 